\title{
Efeitos da redução ou substituição do soro fetal bovino por outros compostos na maturação in vitro de oócitos bovinos ${ }^{1}$
}

\author{
Maite Del Collado ${ }^{2 *}$, Naiara Z. Saraiva ${ }^{3}$, Flavia L. Lopes ${ }^{4}$, Maria Helena Cruz $^{5}$, \\ Roberta C. Gaspar ${ }^{2}$, Clara S. Oliveira ${ }^{6}$, Felipe Perecin ${ }^{5}$ e Joaquim M. Garcia ${ }^{2}$
}

\begin{abstract}
Del Collado M., Saraiva N.Z., Lopes F.L., Cruz M.H., Gaspar R.C., Oliveira C.S., Perecin F. \& Garcia J.M. 2014. [Effects of reduction or replacement of fetal calf serum by other compounds during in vitro maturation of bovine oocytes.] Efeitos da redução ou substituição do soro fetal bovino por outros compostos na maturação in vitro de oócitos bovinos. Pesquisa Veterinária Brasileira 34(7):689-694. Departamento de Medicina Veterinária Preventiva e Reprodução Animal, Faculdade de Ciências Agrárias e Veterinária, Universidade Estadual Paulista, Via de acesso Prof. Paulo Donato Castellane s/n, Jaboticabal, SP 14884-900, Brazil. E-mail: delcollado@hotmail.com

The use of fetal calf serum (FCS), although widely employed during in vitro production (IVP) of bovine embryos, has limitations. FCS is an undefined media and may have harmful effects on the quality of embryos. For this reason, in recent years, research efforts aimed at improving IVP of bovine embryos, have focused at the replacement of FCS by alternative compounds in culture media. In this study, fatty acid free bovine serum albumin (BSA-FAF) and embryonic fluid (EF) were used separately or in combination, in different concentrations, to replace or reduce the concentration of FCS during in vitro maturation (IVM). For this purpose, bovine oocytes were in vitro matured under different treatments and were assigned to one of the following groups $(\mathrm{G})$ according to the protein supplementation: G1 (control) $=10 \% \mathrm{FCS}, \mathrm{G} 2=8 \mathrm{mg} / \mathrm{mL} \mathrm{BSA}-\mathrm{FAF}, \mathrm{G} 3=10 \% \mathrm{EF}, \mathrm{G} 4=6 \mathrm{mg} / \mathrm{mL} \mathrm{BSA}-\mathrm{FAF}+5 \%$ $\mathrm{FCS}, \mathrm{G} 5=6 \mathrm{mg} / \mathrm{mL} \mathrm{BSA}-\mathrm{FAF}+3.5 \% \mathrm{FCS}+1.5 \% \mathrm{EF}, \mathrm{G} 6=6 \mathrm{mg} / \mathrm{mL} \mathrm{BSA}-\mathrm{FAF}+1.5 \% \mathrm{FCS}+$ $3.5 \% \mathrm{EF}, \mathrm{G} 7=6 \mathrm{mg} / \mathrm{mL}$ BSA-FAF $+5 \% \mathrm{EF}$, and G8 $=5 \% \mathrm{FCS}+5 \% \mathrm{EF})$. After 24 hours of IVM, oocytes were classified according to the meiotic progression and migration of cortical granules (CG) to the periphery. Maturation rates were evaluated by chi-square test $(\chi 2)$ or, when appropriate, by Fisher's exact test, and orthogonal contrasts were performed to isolate effects of the compounds. The group supplemented with BSA-FAF (G2) had a lower number of oocytes that reached MII (75\%) compared to the groups G1, G4, G5 and G8 $(88.9 \%, 89.6 \%, 87 \%$ and $86.8 \%$, respectively), with no difference in relation to G3 (79.8\%), G6 (82.9\%) and G7 (82.9\%). Moreover, G3 also showed inferior nuclear maturation rate when compared to G4. Regarding cytoplasmic maturation, the rates were reduced to $43.9 \%, 43.2 \%, 43.1 \%$ and $36.5 \%$ in G2, G7, G6 and G3 groups, respectively, compared to the control group (G1; 62.4\%). On the other hand, in the groups G8, G4 and G5, maturation rates were not affected by reduction of FCS, where $59.3 \%, 51.3 \%$ and $50.8 \%$ of the oocytes displayed CG arranged peripherally, respectively. The results obtained by the orthogonal contrast test are in accordance with the ones from the evaluation of the nuclear maturation
\end{abstract}

\footnotetext{
${ }^{1}$ Recebido em 20 de dezembro de 2013.

Aceito para publicação em 9 de abril de 2014.

${ }^{2}$ Departamento Medicina Preventiva e Reprodução Animal, Faculdade de Ciências Agrárias e Veterinárias (FCAV), Universidade Estadual Paulista (Unesp), Jaboticabal, SP 14884-900, Brasil. E-mails: nairavet@hotmail. com, roberta_cordeirogaspar@hotmail.com, jmgarcia@fcav.unesp.br; *Autor para correspondência: delcollado@hotmail.com

${ }^{3}$ Embrapa Amazônia Oriental, Belém, PA 66095-100, Brasil. E-mail: naiara.saraiva@embrapa.br
}

\footnotetext{
${ }^{4}$ Departamento de Apoio, Produção e Saúde Animal, Faculdade de Medicina Veterinária, Unesp, Araçatuba, SP 16050-680, Brasi. E-mail: flavialopes@fmva.unesp.br

${ }^{5}$ Departamento de Medicina Veterinária, Faculdade de Zootecnia e Engenharia de Alimentos, Universidade de São Paulo (USP), Pirassununga, SP 13.635-900, Brasil. E-mails: leninha_cruz@hotmail.com, fperecin@ usp.br

${ }^{6}$ Embrapa Gado de Leite, Valença, RJ 27610-000, Brasil. E-mail: claraslade@gmail.com
} 
and cortical granules migration. These data show the need of FCS on the MIV, even in low concentrations, and the possibility of decrease its concentration by associating it with BSA-FAF and/or EF. Therefore, we concluded that it is possible to reduce the concentration of FCS in IVM medium to a concentration of $3.5 \%$ without affecting nuclear and cytoplasmic maturation rates.

INDEX TERMS: Oocytes, in vitro maturation, fetal calf serum, cattle.

RESUMO.- A utilização do soro fetal bovino (SFB), embora bastante disseminada na produção in vitro (PIV) de embriões bovinos, apresenta limitações por ser um meio indefinido e por causar efeitos que prejudicam a qualidade desses embriões. Por esse motivo, nos últimos anos, grande parte das pesquisas relacionadas à PIV está voltada para a substituição do SFB por outros compostos nos meios de cultura. No presente estudo, foram utilizados como compostos protéicos a albumina sérica bovina livre de ácidos graxos (BSA-FAF) e um produto comercial denominado fluido embriônico (FE) de maneira isolada ou em diferentes combinações e concentrações, com objetivo de substituir ou diminuir a concentração do SFB durante a maturação in vitro (MIV). Para isso, oócitos bovinos foram maturados in vitro nos seguintes grupos $(\mathrm{G})$ que foram delineados de acordo com a suplementação protéica recebida: G1 (controle) $=10 \%$ de $\mathrm{SFB}, \mathrm{G} 2=8 \mathrm{mg} / \mathrm{mL}$ de BSA-FAF, G3 $=10 \%$ de FE, G4 $=6 \mathrm{mg} /$ $\mathrm{mL}$ de BSA-FAF $+5 \%$ de SFB, G5 $=6 \mathrm{mg} / \mathrm{mL}$ de BSA-FAF + $3,5 \%$ de SFB $+1,5 \%$ de FE, G6 $=6 \mathrm{mg} / \mathrm{mL}$ de BSA-FAF $+1,5 \%$ de SFB $+3,5 \%$ de FE, G7 $=6 \mathrm{mg} / \mathrm{mL}$ de BSA-FAF $+5 \%$ de FE e G8 = 5\% de SFB + 5\% de FE. Após 24 horas de MIV, os oócitos foram classificados de acordo com a progressão meiótica e migração dos grânulos corticais (GC). As taxas de maturação foram avaliadas pelo teste do Qui-Quadrado $\left(\chi^{2}\right)$ ou, quando apropriado, pelo teste exato de Fisher, e para o estudo dos efeitos dos suplementos foram realizados contrastes ortogonais. 0 grupo suplementado com BSA-FAF (G2) mostrou diminuição na taxa de oócitos que atingiram MII (75\%) em comparação aos grupos G1, G4, G5 e G8 (88,9\%, $89,6 \%, 87 \%$ e $86,8 \%$, respectivamente), sem diferir do do G3 $(79,8 \%)$, G6 $(82,9 \%)$ e G7 $(82,9 \%)$. Ademais, o G3 também apresentou diminuição na taxa de maturação nuclear quando comparado ao G4. Quanto à maturação citoplasmática, nos grupos G2, G7, G6 e G3, houve redução $(p<0,05)$ das taxas para $43,9 \%, 43,2 \%, 43,1 \%$ e $36,5 \%$, respectivamente, quando comparadas ao meio controle (G1), que permitiu a obtenção de valores médios de $62,4 \%$. Por outro lado, nos grupos G8, G4 e G5, a taxa de maturação citoplasmática não foi afetada com a redução do SFB, onde 59,3\%, 51,3\% e $50,8 \%$ dos oócitos apresentaram os GC dispostos na periferia, respectivamente. Os resultados obtidos pelo teste de contrastes ortogonais complementam os obtidos na avaliação da maturação nuclear e migração de grânulos corticais, mostrando a necessidade do SFB durante a MIV, mesmo que em baixas concentrações, e a possibilidade de diminuir a sua concentração associando-o a BSA-FAF e/ou FE. Dessa forma, conclui-se que é possível reduzir a concentração de SFB no meio de MIV para até 3,5\% sem prejuízo significativo aos índices de maturação nuclear e citoplasmática.

TERMOS DE INDEXAÇÃO: Oócitos bovinos, maturação in vitro, soro fetal bovino.

\section{INTRODUÇÃO}

Apesar de inúmeras pesquisas objetivando aumentar as taxas de produção in vitro (PIV) de embriões bovinos, atualmente, ainda apenas $40-50 \%$ dos oócitos maturados e fertilizados in vitro chegam ao estádio de blastocisto (Rizos et al. 2002). Esses valores diferem daqueles observados na maturação in vivo, em que $70 \%$ dos oócitos alcançam o estádio de blastocisto mesmo quando o cultivo é feito in vitro, mostrando que, os oócitos maturados in vitro são menos competentes para o desenvolvimento embrionário que aqueles maturados in vivo (Lonergan et al. 2006).

Sabe-se que as maiores taxas de maturação oocitária são obtidas quando o meio é suplementado com fontes protéicas de origem animal, tais como o soro fetal bovino (SFB) (Vanroose et al. 2001). 0 soro tem vários componentes que melhoram o desenvolvimento embrionário, como fatores de crescimento, quelantes de metais pesados e componentes que ajudam na expansão das células do cumulus (Abe \& Hoshi 2003). Porém, também existem alguns inconvenientes com o uso do soro na PIV, podendo ocasionar alterações na ultra estrutura, compactação e blastulação embrionária, assim como na expressão de RNAm, além da possibilidade de aumentar a incidência de natimortos e mortalidade após o nascimento (Abe et al. 1999). Além disso, a utilização do SFB apresenta o risco de contaminação nos meios de cultivo por patógenos, tanto virais como príons, aumentando o risco de doenças como, por exemplo, a encefalopatia espongiforme bovina (EEB) e a diarréia viral bovina (BVD) (Abe et al. 1999, Räty et al. 2011). Outro fator negativo relacionado ao SFB é o acúmulo lipídico. Aparentemente, o soro altera o metabolismo embrionário nas primeiras etapas do desenvolvimento, aumentando a concentração de ácidos graxos e gotas lipídicas citoplasmáticas nos blastocistos e diminuindo a criotolerância embrionária (Rizos et al. 2003).

Dessa forma, tem sido proposto o uso de substitutos para o SFB, como o polivilinilpirrolidona (PVP), o alcoolpolivinílico (PVA) e o substituto sintético de soro (SSS), que foram testados tanto na maturação in vitro (MIV) de oócitos quanto no cultivo in vitro (CIV) de embriões bovinos. Porém, existem limitações para o uso desses compostos visando à obtenção de boas taxas de embriões na PIV quando utilizados isoladamente (Ali et al. 2002, Lim et al. 2007, Sayirkava et al. 2007).

A albumina sérica bovina (BSA) é um suplemento protéico semi-definido normalmente utilizado na substituição do soro nos meios de cultura. A adição da BSA nos meios de cultura proporciona taxas de blastocistos e criotolerância satisfatórias quando é utilizada no cultivo in vitro (CIV) (Gomez et al. 2008). No entanto, apresenta resultados diferentes quando utilizada na MIV, havendo estudos relatando 
uma diminuição nas taxas de maturação e/ou desenvolvimento embrionário (Ali et al. 2002, Korhonen et al. 2010), e estudos relatando taxas satisfatórias (Rusell et al. 2006). Recentemente, pesquisas mostraram a possibilidade do uso de suplementos alternativos, como o produto comercial Fluido Embriônico (FE), com resultados satisfatórios nas taxas de maturação oocitária, produção de blastocistos e criotolerância embrionária (Tetzner et al. 2010, De Lima et al. 2012).

Considerando os resultados promissores dessas fontes proteicas alternativas, esse estudo teve como objetivo avaliar os efeitos da substituição parcial ou total do SFB por BSA ou FE ou as combinações deles durante a MIV em bovinos.

\section{MATERIAL E MÉTODOS}

Produtos químicos. Produtos químicos e meios foram adquiridos da Sigma Chemical Co. (St. Louis, MO, USA), a menos que indicado de outra forma.

Obtenção e seleção dos complexos cumulus oócito (COCs). Ovários foram obtidos de fêmeas bovinas provenientes de abatedouro, e transportados até o laboratório em garrafa térmica contendo solução salina a $32-36^{\circ} \mathrm{C}$. Os ovários foram então lavados com solução salina $\left(32-36^{\circ} \mathrm{C}\right)$, e folículos entre 3 e $8 \mathrm{~mm}$ foram aspirados com a ajuda de agulhas $(30 \times 10 \mathrm{~mm})$ acopladas à seringas de $20 \mathrm{~mL}$. 0 líquido folicular recuperado foi depositado em tubos cônicos de $50 \mathrm{~mL}$. Após 15 minutos, o sedimento foi avaliado, procedendo-se à seleção dos COCs. Os oócitos selecionados foram lavados em meio TCM199 suplementado com Hepes (20 mM), bicarbonato de sódio $(5 \mathrm{mM})$, amicacina $(83,4 \mu \mathrm{g} / \mathrm{mL})$, e piruvato de sódio $(0,2 \mathrm{mM})$ e classificados em GI, GII, GIII, desnudos e atrésicos, pelo número de camadas de células do cumulus e homogeneidade do citoplasma (Leibfried-Rutledge et al. 1987).

Maturação in vitro dos oócitos. Os COCs de GI e GII foram distribuídos aleatoriamente nos diferentes grupos de MIV em meio base TCM199 suplementado com 25mM de bicarbonato de sódio, $1,0 \mu \mathrm{g} / \mathrm{mL}$ de FSH (Pluset ${ }^{\circledR}$, Calier), $50 \mu \mathrm{g} / \mathrm{mL}$ de hCG (Profasi ${ }^{\circledR}$, Serono), 1,0 $\mu \mathrm{g} / \mathrm{mL}$ de estradiol, $0,20 \mathrm{mM}$ de piruvato de sódio, e 83,4 $\mu \mathrm{g} / \mathrm{mL}$ de amicacina. Esses meios foram suplementados com os seguintes compostos protéicos, de acordo com o tratamento proposto: soro fetal bovino (SFB) (Cripion, Industria Brasileira, Andradina, SP, BR), albumina sérica bovina-livre de ácidos graxos (BSA-FAF) (A8806) e/ou fluido embriônico (FE) (E1761).

De acordo com a suplementação protéica recebida, foram delineados os seguintes grupos (G): G1 (controle) $=10 \%$ de SFB, G2 = $8 \mathrm{mg} / \mathrm{mL}$ de BSA-FAF, G3 $=10 \%$ de FE, G4 $=6 \mathrm{mg} / \mathrm{mL}$ de BSA-FAF $+5 \%$ de SFB, G5 $=6 \mathrm{mg} / \mathrm{mL}$ de BSA-FAF $+3,5 \%$ de SFB $+1,5 \%$ de $\mathrm{FE}, \mathrm{G} 6=6 \mathrm{mg} / \mathrm{mL}$ de BSA-FAF $+1,5 \%$ de SFB $+3,5 \%$ de FE, G7 = $6 \mathrm{mg} / \mathrm{mL}$ de BSA-FAF $+5 \%$ de FE e G8 $=5 \%$ de SFB $+5 \%$ de FE). As placas de maturação com os diferentes tratamentos foram devidamente identificadas e mantidas em incubadora a $38,5^{\circ} \mathrm{C}$ e $5 \%$ de $\mathrm{CO}_{2}$ em ar e umidade alta por 24 horas. Os dados foram obtidos a partir de quatro rotinas de MIV.

Avaliações da maturação nuclear e citoplasmática dos oócitos. A maturação nuclear foi avaliada pela progressão meiótica até Metáfase II (MII) com a extrusão do primeiro corpúsculo polar, e a citoplasmática inferida pela migração dos grânulos corticais (GC) até a região cortical oocitária. Para isso, foi utilizada a metodologia descrita por Cherr et al. (1998) e Avelino (2004) com modificações.

Primeiramente foram removidas as células do cumulus dos COCs com diversas pipetagens em $0,2 \%$ de hialuronidase (Hyalozima $^{\circledR}$, Aspen) em PBS. Os oócitos destinados à avaliação da ma- turação nuclear foram fixados em paraformaldeido (4\% em PBS), e aqueles destinados à avaliação citoplasmática foram fixados em formaldeído (3\% em PBS) após a remoção da zona pelúcida (ZP) com pronase $0,5 \%$ em PBS. Em seguida, todos os oócitos foram incubados por 12 horas, a $4^{\circ} \mathrm{C}$, em solução de bloqueio (SB) [PBS com $1 \mathrm{mg} / \mathrm{mL}$ de albumina sérica bovina, $100 \mathrm{mM}$ de glicina (PlusOne, GE Healthcare, New Jersey, USA ) e 0,2\% de azida de sódio].

Os oócitos livres de ZP foram corados para a avaliação dos GC, sendo permeabilizados em uma solução de bloqueio (SB) acrescida com $0,1 \%$ de Triton X-100 (USB 22686) por 5 minutos a $38^{\circ} \mathrm{C}$, incubados em $10 \mu \mathrm{g} / \mathrm{mL}$ de Lens culinaris aglutinina conjugada a isotiocianato de fluoresceína (FITC-LCA) por 15minutos, e lavados de duas a três vezes em SB. Os oócitos para a avaliação da progressão meiótica foram corados em $10 \mu \mathrm{g} / \mathrm{mL}$ de Hoechst $33342 \mathrm{em} \mathrm{SB}$ por 10 minutos e posteriormente lavados em SB repetidamente.

Depois de corados, os oócitos foram colocados, separadamente, entre lâmina e lamínula em uma gota de glicerol. Para a visualização das estruturas, foi utilizado microscópio de epifluorescência (Olympus, IX-FLA-70, Tóquio, Japão), onde os oócitos foram avaliados quanto à maturação nuclear (excitação 330-385nm e emissão 420-490nm para o Hoechst) e quanto à maturação citoplasmática (excitação 460-490nm e emissão 515nm, para o FITC). Oócitos em MII e com presença do primeiro corpúsculo polar foram considerados maturos em relação à avaliação da maturação nuclear, enquanto os que se encontravam em outros estádios foram considerados imaturos. Na avaliação da maturação citoplasmática, oócitos com os grânulos corticais dispostos na periferia formando um halo, foram considerados maturos, e oócitos com presença de "clusters" ou em transição, imaturos.

Análise estatística. As taxas de maturação foram avaliadas pelo teste do Qui-Quadrado $\left(\chi^{2}\right)$ ou, quando apropriado, pelo teste exato de Fisher, e para o estudo dos efeitos dos suplementos, foram realizados contrastes ortogonais. Foi utilizado o programa GraphPadPrism 4.0 (GraphPadPrismInc, San Diego, EUA) e o nível de significância foi de $5 \%$.

\section{RESULTADOS E DISCUSSÃO}

No presente trabalho, o grupo suplementado exclusivamente com BSA-FAF (G2) mostrou deficiência quanto à maturação nuclear, apresentando menor porcentagem (75\%) de oócitos em MII após 24 horas de MIV em comparação aos grupos G1, G4, G5 e G8, que atingiram taxas de $88,9 \%$, $89,6 \%, 87 \%$ e $86,8 \%$, respectivamente, sem diferir dos

Quadro 1. Taxas de oócitos bovinos maturos nuclearmente (em MII) e com GC dispostos na periferia após 24 horas de maturação in vitro nas diferentes suplementações

\begin{tabular}{ccc}
\hline Grupos & $\begin{array}{c}\text { Oócitos em MII } \\
\text { n }(\%)\end{array}$ & $\begin{array}{c}\text { Oócitos com GC na } \\
\text { periferia } \mathrm{n}(\%)\end{array}$ \\
\hline 1 & $104 / 117(88,9)^{\mathrm{ab}}$ & $78 / 125(62,4)^{\mathrm{a}}$ \\
2 & $69 / 92(75)^{\mathrm{c}}$ & $54 / 123(43,9)^{\mathrm{bc}}$ \\
3 & $87 / 109(79,8)^{\mathrm{bc}}$ & $42 / 115(36,5)^{\mathrm{c}}$ \\
4 & $95 / 106(89,6)^{\mathrm{a}}$ & $58 / 113(51,3)^{\mathrm{ab}}$ \\
5 & $87 / 100(87)^{\mathrm{ab}}$ & $65 / 128(50,8)^{\mathrm{ab}}$ \\
6 & $92 / 111(82,9)^{\mathrm{ac}}$ & $59 / 137(43,1)^{\mathrm{bc}}$ \\
7 & $97 / 117(82,9)^{\mathrm{ac}}$ & $54 / 125(43,2)^{\mathrm{bc}}$ \\
8 & $105 / 121(86,8)^{\mathrm{ab}}$ & $70 / 118(59,3)^{\mathrm{a}}$
\end{tabular}

$\overline{a, b, c}$ Valores com sobrescritos diferentes entre linhas dentro de uma mesma coluna, diferem entre si (Qui-quadrado, $\mathrm{p}<0,05$ ). Grupos: G1 (controle) $=10 \%$ de SFB, G2 $=8 \mathrm{mg} / \mathrm{mL}$ de BSA-FAF, G3 $=10 \%$ de FE, G4 $=6 \mathrm{mg} /$ $\mathrm{mL}$ de BSA-FAF $+5 \%$ de SFB, G5 $=6 \mathrm{mg} / \mathrm{mL}$ de BSA-FAF $+3,5 \%$ de SFB + $1,5 \%$ de $\mathrm{FE}, \mathrm{G} 6=6 \mathrm{mg} / \mathrm{mL}$ de BSA-FAF $+1,5 \%$ de $\mathrm{SFB}+3,5 \%$ de $\mathrm{FE}, \mathrm{G} 7=$ $6 \mathrm{mg} / \mathrm{mL}$ de BSA-FAF $+5 \%$ de FE e G8 $=5 \%$ de SFB $+5 \%$ de FE. 
grupos G3 (79,8\%), G6 (82,9\%) e G7 (82,9\%) (Quadro 1). Além disso, a MIV suplementada com FE (G3) levou a uma diminuição da média de oócitos em MII quando comparada ao G4.

Quanto à avaliação da migração dos CG até a periferia do citoplasma durante a MIV como indício de maturação citoplasmática, o G2 apresentou menores índices $(\mathrm{p}<0,05)$, de maneira similar aos grupos G7, G6 e G3, sendo que as taxas obtidas foram de $43,9 \%, 43,2 \%, 43,1 \%$ e $36,5 \%$, respectivamente, enquanto no grupo controle (G1) a média foi de 62,4\% (Quadro 1). Assim, observou-se que tanto nos grupos compostos por meios contendo BSA-FAF e FE isoladamente, como naqueles em que o SFB estava presente em uma proporção menor $(1,5 \%)$, não foi possível a obtenção de taxas de maturação citoplasmática satisfatórias, verificando-se, portanto, uma limitação na capacidade desses compostos proteicos alternativos, ou na redução acentuada do SFB, de proporcionar adequados índices de maturação citoplasmática.

Os achados do presente estudo sinalizam para um efeito prejudicial da BSA durante a MIV, não somente sobre a migração dos GC até a periferia do oócito, mas também sobre a maturação nuclear, corroborando com relato prévio que mostra ação retardante dessa substância na quebra da vesícula germinativa (GVBD) e, consequentemente, na progressão meiótica até MII (Ali et al. 2002).

Uma provável causa desse retardo na maturação nuclear constatado no G2, estaria relacionada à ausência de ácidos graxos no meio, uma vez que a oxidação dos ácidos graxos repercute na maturação nuclear, ajudando na reativação da meiose, como demonstram estudos realizados em camundongos (Downs et al. 2009). Em estudo prévio, realizamos a quantificação dos ácidos graxos presentes no meio contendo $10 \%$ de SFB por meio da cromatografia gasosa do soro, e tendo em consideração as indicações do fabricante sobre o teor lipídico da BSA-FAF $(\leq 0,02 \%)$, verificamos que o meio contendo $10 \%$ de SFB proporciona dezoito vezes mais ácidos graxos do que o meio contendo apenas BSA (Del Collado et al. 2013). Neste contexto, a teoria de Downs et al. (2009) corrobora com as maiores taxas de maturação obtidas no presente estudo a partir de meios MIV ricos em lipídeos, como os suplementados com SFB, apoiando a hipótese dos autores sobre a necessidade do SFB durante o processo de MIV.

No presente experimento, observou-se uma falta de expansão das células do cumulus na maioria dos oócitos maturados na presença do BSA-FAF. Mesmo sendo uma avaliação qualitativa, a falta de expansão poderia ser justificada pela correlação negativa existente entre os oócitos maturados nesse composto quanto à produção de acido hialurônico (Russell et al. 2006). 0 papel que desenvolve a expansão das células do cumulus na maturação tem sido bem discutido, e enquanto há autores que afirmam que a expansão não tem relação com a maturação citoplasmática por não interferir na expressão de genes marcadores oocitários (Calder et al. 2005), tem autores que destacam o impacto da expansão na fertilização e desenvolvimento embrionário (Furnus et al. 1998).

Assim, o SFB parece ser um composto importante para a maturação, tanto nuclear quanto citoplasmática, prova- velmente por conter diversos fatores de crescimento que promovem a maturação, fazendo com que a mesma seja prejudicada na ausência do SFB, como acontece quando a MIV é suplementada exclusivamente com BSA-FAF.

Com relação ao FE, os resultados encontrados nesse trabalho diferem dos achados por Tetzner et al. (2011), onde o uso da mesma concentração de FE no meio de MIV (10\%) não prejudicou as taxas de maturação em comparação ao meio com SFB. Entretanto, o uso desse produto comercial ainda é recente, não havendo consenso em relação à padronização das melhores condiç̧ões para sua utilização, ou até mesmo na padronização na obtenção do FE (período gestacional ao momento da obtenção entre outros fatores), o que poderia levar a diferenças entre lotes.

Os grupos que forneceram resultados próximos aos obtidos pelo grupo controle (10\% de SFB) em relação à maturação citoplasmática foram aqueles que continham combinações entre SFB (mínimo de 3,5\%) e os outros compostos, como nos grupos G8 ( $5 \%$ de SFB + 5\% de FE), G4 (5\% de $\mathrm{SFB}+\mathrm{BSA}-\mathrm{FAF})$ e G5 $(3,5 \% \mathrm{SFB}+\mathrm{BSA}-\mathrm{FAF}+1,5 \% \mathrm{FE})$, que propiciaram taxas de $59,3 \%, 51,3 \%$ e $50,8 \%$, respectivamente. Esse foi o primeiro estudo que propôs a avaliação conjunta da diminuição na concentração do SFB na MIV sobre a maturação nuclear e migração dos grânulos corticais, demonstrando a possibilidade de diminuição para até $3,5 \%$, sem alterações das taxas de maturação oocitária. 0 grupo de pesquisa de Russel et al. (2006) observou que a MIV contendo $10 \%$ de SFB leva a uma maior expansão das células do cumulus e fornece ooplasmas bem mais escuros em comparação à utilização de menores concentrações de SFB (2\%) ou de BSA, sendo que citoplasmas escurecidos são normalmente relacionados ao aumento de lipídeos e diminuição da criosobrevivência. Além disso, como relatado nesse trabalho, o número de células totais e o padrão de expressão gênica dos embriões cultivados nos diferentes meios de maturação, BSA e SFB, são diferentes, observando-se os efeitos que a concentração do soro pode causar nos oócitos e embriões.

Os resultados obtidos pelo teste de contrastes ortogonais (Quadro 2) complementam-se aos obtidos na avaliação da maturação nuclear e migração de grânulos corticais. Como apresentado no primeiro contraste, observamos que não há efeito de sinergismo entre os compostos, sendo que também não se observa nenhum efeito prejudicial ao serem associados. Porém, o contraste da comparação entre o meio contento unicamente BSA-FAF e os meios com BSA-FAF associado, demostra, mais uma vez, a dificuldade que este composto apresenta em atingir boas taxas de maturação nuclear quando utilizado isoladamente. Como mencionado anteriormente, este teste também verificou que o SFB, mesmo em concentrações menores, é necessário para ocorrer taxas satisfatórias de progressão meiótica e migração de grânulos corticais e que há possibilidade de se reduzir a porcentagem do SFB até $3.5 \%$, associando-o a outros compostos, sem que as taxas de maturação oocitária sejam afetadas.

Há tempos procura-se um substituto para o soro que não prejudique a maturação e competência oocitária, assim como as taxas e qualidade embrionárias. Vários estudos 
Quadro 2. Resultado do teste de contrastes ortogonais para isolar os efeitos dos suplementos SFB, BSA-FA e FE durante a maturação in vitro de oócitos bovinos sobre a maturação nuclear e migração dos grânulos corticais. Dados obtidos de quatro repetições

\begin{tabular}{lcc}
\hline \multicolumn{1}{c}{ Contrastes } & $\begin{array}{c}\text { Significância para a } \\
\text { maturação nuclear (p) }\end{array}$ & $\begin{array}{c}\text { Significância para a migração } \\
\text { dos grânulos corticais (p) }\end{array}$ \\
\hline Suplementos isolados versus associados & 0,1362 & 0,7986 \\
Contendo SFB versus sem SFB & 0,0073 & 0,0127 \\
Contendo BSA-FAF versus sem BSA-FAF & 0,2484 & 0,1267 \\
Contendo FE versus sem FE & 0,4574 & 0,2267 \\
SFB isolado versus SFB associado a BSA-FAF e/ou FE & 0,3384 & 0,0742 \\
BSA-FAF isolado versus BSA-FAF associado a SFB e/ou FE & 0,0157 & 0,4735 \\
FE isolado versus FE associado a SFB e/ou BSA-FAF & 0,3078 & 0,1482 \\
5\% de SFB versus $\leq 3,5 \%$ de SFB & 0,0668 & 0,2536
\end{tabular}

Valores de p<0,05 foram considerados significantes. Grupos: G1 (controle) $=10 \%$ de SFB, G2 $=8 \mathrm{mg} / \mathrm{mL}$ de BSA-FAF, $\mathrm{G} 3=10 \%$ de FE, G4 $=6 \mathrm{mg} / \mathrm{mL}$ de BSA-FAF $+5 \%$ de SFB, G5 $=6 \mathrm{mg} / \mathrm{mL}$ de BSA-FAF $+3,5 \%$ de SFB $+1,5 \%$ de FE, $\mathrm{G} 6=6 \mathrm{mg} / \mathrm{mL}$ de BSA-FAF $+1,5 \%$ de SFB $+3,5 \%$ de FE, G7 $=6 \mathrm{mg} / \mathrm{mL}$ de BSA-FAF $+5 \%$ de FE e G8 = 5\% de SFB + $5 \%$ de FE.

apontavam o PVP como o melhor candidato para a substituição do soro na MIV, por permitir, em concentrações controladas, a obtenção de boas taxas de blastocisto. Apesar disso, pesquisas mostraram que a MIV na presença desse composto diminui a expansão das células do cumulus, e que a utilização de altas concentrações dessa macromolécula retarda a maturação nuclear e diminui as taxas de PIV (Ali et al. 2002). Além disso, pode-se observar alterações nos padrões de expressão gênica embrionários e aumento nos índices de apoptose nos blastocistos cultivados com PVP, o que percutiria na qualidade desses embriões (Warzyrch et al. 2007). Assim, percebe-se a complexidade para a substituição do soro no meio MIV por compostos definidos que proporcionem taxas satisfatórias de produção e qualidade embrionária, sendo que a diminuição da concentração do SFB juntamente à adição de outros compostos semi ou definidos torna-se uma estratégia bastante promissora.

Segundo o fabricante, o fluido embriônico é um composto de fatores de crescimento e de hormônios que tem sido muito utilizado na cultura de células, mostrando bons resultados quando associado ao SFB e podendo ser um substituto para o mesmo por fornecer resultados semelhantes. Porém, trata-se de um meio indefinido e, assim, maiores estudos dessa fonte alternativa devem ser realizados, antes que a mesma seja utilizada rotineiramente na MIV. Desde que melhor caracterizada, inclusive quanto ao acúmulo lipídico e qualidade dos embriões produzidos, pode ser utilizada em combinação com o SFB.

Neste estudo, a combinação entre o BSA-FAF e o SFB na maturação possibilitou a obtenção de adequadas taxas de maturação oocitária. Esse achado é interessante pelo fato de que a concentração do SFB pode ser reduzida pela metade quando esse composto é associado à BSA-FAF no sistema de MIV. É de grande interesse o estudo mais aprofundado dessa combinação, pois é esperado que ocorra menor acúmulo de gotas lipídicas citoplasmáticas nesses oócitos, o que pode ser refletido na melhoria da criosobrevivência dos embriões produzidos.

\section{CONCLUSÃO}

Concluímos que a substituição total do SFB durante a MIV pela BSA-FAF não permite a obtenção de taxas de matura- ção satisfatórias. No entanto, existe a possibilidade de diminuição da concentração do SFB para até 3,5\%, quando o mesmo é associado à BSA-FAF e/ou FE, sem que as taxas de maturação nuclear e citoplasmática sejam alteradas. Assim, recomendam-se estudos futuros que avaliem os reflexos deste sistema de MIV no desenvolvimento embrionário e criopreservação dos embriões produzidos.

Agradecimentos.- À Coordenação de Aperfeiçoamento de Pessoal de Nível Superior (CAPES) pelo apoio financeiro, e à equipe do Laboratório de Reprodução Animal da Faculdade de Ciências Agrárias e Veterinárias da UNESP de Jaboticabal (SP) pelo apoio na execução desse experimento.

\section{REFERÊNCIAS}

Abe H., Yamashita S., Itoh T., Satoh T. \& Hoshi H. 1999. Ultrastructure of bovine embryos developed from in vitro matured and -fertilized oocytes: comparative morphological evaluation of embryos cultured either in serum-free medium or in serum-supplemented medium. Molec. Reprod. Develop. 53:325-335.

Abe H. \& Hoshi H. 2003. Evaluation of bovine embryos produced in high performance serum-free media. J. Reprod. Develop. 49:193-202.

Ali A. \& Sirad MA. 2002. Effect of the absence or presence of various protein supplements on further development of bovine oocyte during in vitro maturation. Biol. Reprod. 66:901-05.

Avelino K.B. 2004. Estimulação e inibição da síntese de glutationa em oócitos bovinos: efeitos sobre a maturação e desenvolvimento embrionário in vitro. Tese de Doutorado em Medicina Veterinária, Reprodução Animal, Universidade Estadual Paulista, Jaboticabal, SP. 92p.

Cherr G.N., Drobnis E.Z. \& Katz D.F. 1988. Localization of cortical granule constituents before and after exocytosis in the hamster egg. J. Exp. Zoology 246:81-93.

De Lima M.R., Saraiva N.Z., Oliveira C., del Collado M., Tetzner T.D., Rossi G.F. \& Garcia J.M. 2012. Effects of the use of embryonic fluid during in vitro maturation of bovine oocytes on embryonic development and survival to vitrification. Anim. Reprod. 9:574.

Del Collado M., Saraiva N.Z., Lopes F.L., Gaspar R.G., Padilha L.C., Costa R.R., Rossi G.F., Vantini R. \& Garcia J.M. 2013. Expression of PLIN2 and DGAT2 in cumulus cells, oocytes and embryos following different supplementation during in vitro maturation. $46^{\text {th }}$ Annual Meeting of the Society for the Study of Reproduction, Bioloy of Reproduction, Montreal, Canada, p.187-188 (Abstract 390). <http://www.brightcopy.net/allen/bor/ SSR-46th-meeting/index.php\#/190>

Downs S.M., Mosey J.L. \& Klinger J. 2009. Fatty acid oxidation and meiotic resumption in mouse oocytes. Molec. Reprod. Develop. 76:844-853.

Gómez E., Rodriguez A., Muñoz M., Caamaño J.N., Hidalgo C.O., Morán E., Facal N. \& Diez C. 2008. Serum free embryo culture médium improves 
in vitro survival of bovine blastocysts to vitrification. Theriogenology 69:1013-1021.

Korhonen K., Kananen K., Ketoja E., Matoma J., Halmekyto M. \& Peippo J. 2010. Effect of serum free in vitro maturation of bovine oocyte on subsequent embryo development and cell allocation in two developmental stages of day 7 blastocysts. Reprod. Domest. Anim. 45:42-49.

Leibfried-Rutledge M.L., Critser E.S., Eyestone W.H., Northey D.L. \& First N.L. 1987. Development potential of bovine oocytes maturated in vitro or in vivo. Biol. Reprod. 36:376-383.

Lim K.T., Jang G., Ko K.H., Lee W.W., Park H.J., Kim J.J., Lee S.H., Hwang W.S., Lee B.C. \& Kang S.K. 2007. Improved in vitro bovine embryo development and increased efficiency in producing viable calves using defined media. Theriogenology 67(2):293-302.

Lonergan P., Fair T., Corcoran D. \& Evans A.C. 2006. Effect of culture environment on gene expression and developmental characteristics in IVFderived embryos. Theriogenology 65:137-152.

Rizos D., Fair T., Papadopuolos S., Boland M. \&, Lonergan P. 2002. Developmental, quality and ultraestructural differences between ovine and bovine embryos produced in vivo or in vitro. Molec. Reprod. Develop. 62:320-327.

Rizos D., Gutierrez-Adan A., Perez-Garnelo S., De LaFuenteJ., Boland M.P.
\& Lonergan P. 2003. Bovine embryo culture in the presence or absence of serum: implications for blastocyst development, cryotolerance and Messenger RNA expression. Biol. Reprod. 68:236-243.

Russell D.F., Baqir S., Bordignon J. \& Betts D.H. 2006. The impact of oocyte maturation media on early bovine embryonic development. Molec. Reprod. Develop. 73: 1255-1270.

Sayirkava H., Misirlioglu M., Kaya A., First N.L., Parrish J.J. \& Memili E. 2007. Developmental potential of bovine oocytes cultured in different maturation and culture conditions. Anim. Reprod. Sci. 1001:225240.

Tetzner T.A.D., Saraiva N.Z., Perecin F., Oliveira C.S., Monteiro F.M., Lima M.R., Méo S.C., Ferreira C.R. \& Garcia J.M. 2010. Effect of embryonic fluid and serum replacer as protein sources for in vitro maturation of bovine oocyte. Anim. Reprod. 7(3):332.

Vanroose G., VanSoon A. \& DeKruif A. 2001. From co-culture to defined medium: State of the art and practical considerations. Reprod. Domest. Anim. 36:25-28.

Warzych E., Wrenzycki C., Peippo J. \& Lechniak D. 2007. Maturation medium supplement affect transcript level of apoptosis and cell survival related genes in bovine blastocysts produced in vitro. Molec. Reprod. Develop. 74:280-289. 